\title{
Proposição de uma Metodologia para Identificação de Unidades de Manejo Produtivas em Plantios de Eucalyptus
}

\author{
Itamar Antonio Bognola(1), José Luiz Gava(2),Pedro Jorge Fasolo ${ }^{(3)}$ e Lorena Stolle(4)
}

\begin{abstract}
(1)Embrapa Florestas, Estrada da Ribeira, Km 111, CEP 83411-000, Colombo-PR. E-mail: iabog@cnpf.embrapa.br; (2)Cia. Suzano de Papel e Celulose, Rodovia Raposo Tavares, s/n, Km 168, CEP 18215-280, Itapetininga-SP. E-mail: jgava@suzano.com.br; ${ }^{(3)}$ Pesquisador aposentado da Embrapa Florestas, Rua Maximino Zanon, 336, Apto. 71, Bacaheri, Curitiba-PR. E-mail: pedrofasolo@zipmail.com.br; ${ }^{(4)}$ Mestranda de Engenharia Florestal, Universidade Federal do Paraná - Departamento de Ciências Florestais, Av. Prefeito Lothário Meissner, 900, 80210-170, Curitiba-PR. E-mail: Iorenastolle@yahoo.com.br
\end{abstract}

Resumo - O conhecimento integrado das características do solo e outros elementos do meio ambiente é de fundamental importância para a sustentabilidade e competitividade do setor florestal brasileiro. Este estudo foi desenvolvido com o propósito de identificar unidades de manejo produtivas homogêneas (UMP's). Dados de 128 unidades amostrais foram obtidos em um levantamento pedológico detalhado (escala 1:15.000) realizado em uma propriedade com 4.660 ha, localizada no Planalto Ocidental Paulista, no Município de Araraquara. Os dados originais de cada variável foram analisados por meio de técnicas definidas como "Lógica Fuzzy". A aplicação dessa técnica permitiu estabelecer, de forma simples e precisa, as UMP's, revelando informações importantes para futuras intervenções nessas áreas homogêneas, em termos de produtividade, visando ao aumento ou manutenção da produção. As seguintes unidades de manejo foram identificadas para o cultivo de eucaliptos na área em estudo: boa, moderada, fraca, muito fraca e inapta.

Termos para indexação: Variabilidade espacial, levantamento detalhado de solos, manejo florestal.

\section{Proposal of a Methodology for the Identification of Productive Management Units in Eucalyptus Plantations}

\begin{abstract}
The integrated information of soil characteristics as well as of other elements of the environment is of fundamental importance for the sustainability and competitiveness of the Brazilian forest sector. This study was developed in order to identify a set of productive management units for plantations established with Eucalyptus species, using the method called "Fuzzy Logic". Data were obtained from 128 sampling units from a detailed soil survey (scale 1:15,000) of a 4,660 ha eucalyptus plantation, located in Araraquara county, in the western plateau of the São Paulo State. The proposed method showed a great potential to be used as a tool to support the identification of management units for Eucalyptus sp. planted forests. The following management units were identified for the establishment of Eucalyptus plantations: good, moderate, weak, very weak and inapt.
\end{abstract}

Index terms: Spatial variability, detailed soil survey, forest management.

\section{Introdução}

Inicialmente pouco tecnificada, a cultura do eucalipto ganhou grande impulso nas décadas de 70 e 80, devido aos incentivos fiscais, ao melhoramento genético e ao desenvolvimento de técnicas avançadas de propagação vegetativa e clonagem. Contudo, a rápida expansão da atividade de reflorestamento nas mais diferentes regiões do País e a utilização predominante do gênero Eucalyptus, com seus elevados números de espécies e sua grande capacidade de adaptação às mais variadas condições ecológicas, levaram à necessidade de estudos que possam permitir prever a sua capacidade produtiva nos diferentes ambientes. As regiões de cultivo de eucalipto apresentam uma infinidade de variações ambientais em nível microrregional, como pode ser facilmente constatado quando se observam as diferenças marcantes entre as produtividades florestais de cada área. Para se avaliar um ambiente, no entanto, há necessidade de se identificar segmentos específicos dentro de uma paisagem geral, em se tratando de propriedade agrícola, e, dentro desse estudo de paisagem, buscar a compreensão das interações que aí se processam. 
Desta forma, a importância da estimativa volumétrica de madeira e do Índice de Sítio de forma mais precisa numa empresa se deve a diversas razões. Dentre elas, destacam-se aquelas ligadas ao Setor de Planejamento e Colheita Florestal. Neste caso, a definição destas Unidades de Manejo Produtivas (UMP's), baseada numa "Silvicultura de Precisão" pode, em muitos casos, contribuir de forma adequada para tal propósito. No entanto, outras razões interessam às empresas do ramo florestal, tais como:

a) Diminuir os custos com a manutenção e processamento da rede de parcelas permanentes, denominadas de "Parcelas de Inventário Florestal Contínuo", que são significativos, tanto para as avaliações efetuadas durante o ciclo da floresta, quanto nos inventários de pré-corte;

b) Após o trabalho de definição das Unidades de Manejo, que visa identificar áreas com mesma capacidade produtiva, interessa às empresas como avaliar suas características, no sentido de fornecer subsídios para a definição de técnicas de manejos mais apropriadas a cada situação, considerando os aspectos de sustentabilidade da produção e maximização da rentabilidade da atividade florestal, em vista de algumas UMP's apresentarem produtividades bem abaixo do esperado.

A Silvicultura de Precisão surgiu da necessidade de se considerar a variabilidade espacial e temporal existente em uma área de produção florestal, buscando a redução nas quantidades de insumos a serem aplicados e, consequentemente, a diminuição de custos e impactos ambientais. O termo Silvicultura de Precisão é atribuído a um método de manejo das culturas que objetiva dar tratamento diferenciado em pequenas áreas, dentro de um mesmo talhão, considerando o potencial produtivo das culturas nessas áreas.

Com a adoção das técnicas e conceitos de silvicultura de precisão, surgem questões sobre a interpretação do grande volume de informações e de como usá-las como ferramentas que auxiliem na tomada de decisão, frente à variabilidade espacial existente nas áreas agrícolas brasileiras. Têm-se, por exemplo, dificuldades na interpretação de mapas de produtividade (CARVALHO et al., 2001).

Por outro lado, pesquisadores como Colvin et al. (1997), Sudduth et al. (1997), Molin (2002) e Kitchen et al. (1998) utilizaram mapas de produtividade para definição de unidades de manejo com relativo sucesso.
Com a inclusão de outros mapas temáticos, espera-se um aprimoramento na geração de unidades de manejo, como sugerido por Kitchen et al. (1998).

Segundo Carvalho et al. (2001), uma forma de determinar unidades de manejo é através da comparação de mapas de colheita para diferentes anos. Um método estatístico usualmente utilizado para avaliar diferenças de médias de duas amostras de dados é o teste $t$, de Student. Entretanto, as condições para que este teste seja apropriadamente aplicado são de que as amostras devem ser independentes e normalmente distribuídas. O problema é que essas condições raramente se aplicam em mapas de produtividade, devido às dependências espaciais e temporais das observações.

Ainda, Carvalho et al. (2001) relatam que outra forma de comparação de mapas é através do índice de Kappa (k) de concordância. Esse método testa a associação entre mapas e ajuda a entender se os mapas diferem devido a alguma variação causal ou se há uma real concordância. Há também os métodos de classificação cruzada e coeficiente de similaridade (LORUP, 2008). Embora existam diversas maneiras de se tratar o problema de comparação de mapas, a maioria delas depende de condições pré-estabelecidas que normalmente não se verificam para dados temporais e espacialmente dependentes.

A proposta metodológica apresentada neste trabalho leva em consideração o conhecimento do meio físico, tendo como base o solo e o relevo, para a distinção dos ambientes na definição de unidades de manejo produtivas para o eucalipto. Daí a importância de se levar em conta a interação dos fatores edáficos com os fatores biofísicos, ao se identificar e separar os diferentes ambientes para a implantação dos povoamentos florestais numa determinada região, pois isso subsidiaria melhor não só a predição de produtividades como também a definição de técnicas e de espécies e procedências adequadas a cada unidade de manejo definida.

Nesse aspecto, o levantamento de solos é tecnologia para a identificação e delimitação dos diferentes ambientes existentes, consistindo no melhor estratificador em nível local (RESENDE et al., 2007). A interpretação do levantamento de solos pode fornecer subsídios para a seleção de espécies, a extrapolação de resultados experimentais, a predição de crescimento e da qualidade da madeira, a interpretação à resposta a fertilizações minerais e as definições de técnicas silviculturais (GONÇALVES, 1989). Entretanto, muitas vezes, um 
levantamento detalhado de solos permite identificar, numa determinada área, inúmeras unidades pedológicas de mapeamento que dificultam seu manejo operacional, em vista da grande quantidade de tarefas que teriam de ser diferenciadas para cada unidade.

Assim, para que as atividades silviculturais possam ser operacionais e de fácil aplicação, é necessário reduzir as unidades de mapeamento de solos em cinco a seis unidades de manejo florestal operacionais numa propriedade rural.

O objetivo deste estudo é, portanto, apresentar uma metodologia para determinação de unidades de manejo florestais para a cultura do eucalipto, que leve em consideração os aspectos do meio físico, por meio de técnicas definidas como "Lógica Fuzzy".

\section{Material e Métodos}

A área-piloto em estudo localiza-se no Estado de São Paulo, no Município de Araraquara, na Fazenda Fortaleza, da Empresa Conpacel - Consórcio Paulista de Papel e Celulose (antiga Ripasa S/A), uma empresa do grupo Votorantin associado ao Grupo Suzano, com coordenadas planas aproximadas UTM $802.000 \mathrm{e}$ 815.000 E, e 7.575.000 e 7.592.000 S (Datum SAD 69), e área útil de 4.660 ha.

As principais litologias encontradas na fazenda Fortaleza correspondem às Formações Pirambóia ou Botucatu (CAVAGUTI; SILVA 1992).

Quanto ao clima, a Tabela 1 apresenta o Balanço Hídrico com dados médios climatológicos de 30 anos de coletas para o município de Araraquara, SP (período: 1941 a 1970).

Tabela 1. Balanço hídrico para o Município de Araraquara, SP.

\begin{tabular}{|c|c|c|c|c|c|c|c|}
\hline \multicolumn{2}{|c|}{ Latitude: $21,85 \mathrm{~S}$} & \multicolumn{2}{|c|}{ Longitude: $48,51 \mathrm{~W}$} & \multicolumn{2}{|c|}{ Altitude: $469 \mathrm{~m}$} & \multicolumn{2}{|c|}{ Período: 1941 - 1970} \\
\hline Mês & $\mathrm{T}\left({ }^{\circ} \mathrm{C}\right)$ & $\mathbf{P}(\mathbf{m m})$ & $\operatorname{ETP}(\mathbf{m m})$ & $\operatorname{ARM}(\mathbf{m m})$ & $\operatorname{ETR}(\mathbf{m m})$ & $\operatorname{ETR}(\mathbf{m m})$ & $\operatorname{ETR}(\mathbf{m m})$ \\
\hline Jan & 24,1 & 257 & 120 & 100 & 120 & 0 & 137 \\
\hline Fev & 24,2 & 219 & 110 & 100 & 110 & 0 & 109 \\
\hline Mar & 23,8 & 154 & 112 & 100 & 112 & 0 & 42 \\
\hline Abr & 21,8 & 56 & 83 & 77 & 79 & 3 & 0 \\
\hline Mai & 19,5 & 46 & 62 & 66 & 57 & 5 & 0 \\
\hline Jun & 18,3 & 36 & 49 & 58 & 44 & 5 & 0 \\
\hline Jul & 18,2 & 23 & 49 & 44 & 36 & 29 & 0 \\
\hline Ago & 20,1 & 20 & 65 & 28 & 36 & 29 & 0 \\
\hline Set & 21,7 & 47 & 80 & 20 & 55 & 25 & 0 \\
\hline Out & 22,7 & 128 & 98 & 51 & 98 & 0 & 0 \\
\hline Nov & 23,1 & 147 & 104 & 94 & 104 & 0 & 0 \\
\hline Dez & 23,6 & 199 & 117 & 100 & 117 & 0 & 76 \\
\hline Totais & 261,1 & 1.332 & 1.048 & 837 & 968 & 80 & 364 \\
\hline Médias & 21,8 & 111 & 87 & 70 & 81 & 7 & 30 \\
\hline
\end{tabular}

A Figura 1 mostra as disponibilidades hídricas regional, levando-se em consideração as séries históricas relativas de 30 anos para a respectiva localidade.

Pode-se observar que o padrão climático da disponibilidade hídrica da região é bem característico, com duas estações definidas, sendo uma chuvosa, na primavera-verão, e outra seca no outono-inverno.

Precipitação: a região de Araraquara, SP, caracterizase por possuir elevada pluviosidade no verão e baixa no inverno. 


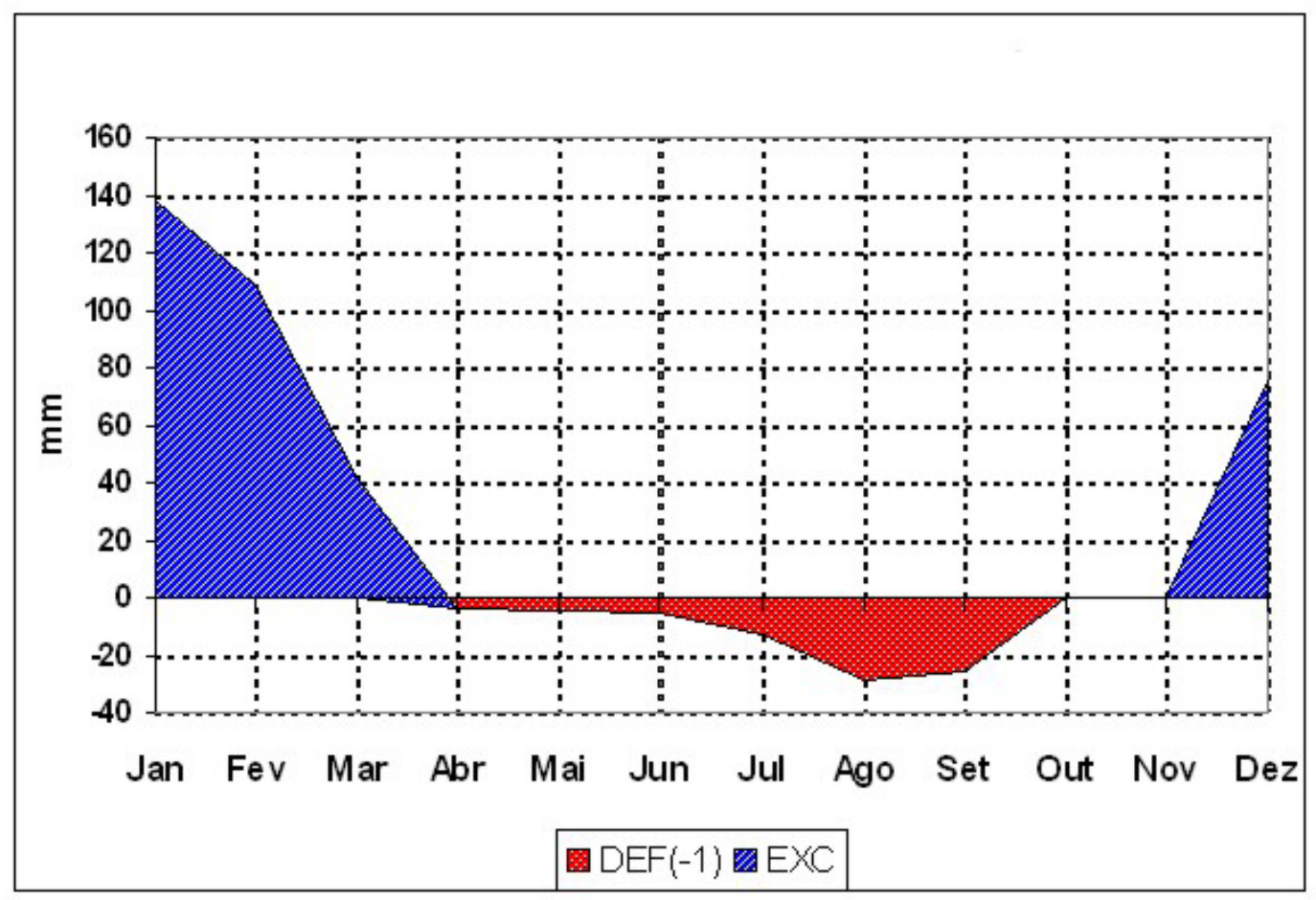

Figura 1. Extrato do Balanço Hídrico Médio Normal Mensal de Araraquara, SP, com EP Calculada por Thornthwaite e Matter (1955), para uma Capacidade de Água Disponível (CAD) $=100 \mathrm{~mm}$. $\mathrm{DEF}=$ Deficiência hídrica $(\mathrm{mm}) ; \mathrm{EXC}=$ Excedente hídrico $(\mathrm{mm})$.

Fonte: DAEE (1941-1970) - Estação de Araraquara, SP.

Portanto, são chuvas bem distribuídas durante a época estival e com baixa precipitação na época mais fria do ano. Consequentemente, há uma estação seca bem definida, suficiente para causar grandes problemas de deficiência hídrica neste período. O valor médio da precipitação anual em Araraquara é de $1.332 \mathrm{~mm}$.

Temperatura: A média anual de temperaturas mais elevadas ocorre no trimestre mais quente (janeiro a março) alcançando $24{ }^{\circ} \mathrm{C}$ no referido município. A temperatura mínima média do trimestre mais frio (maio a julho) é de $18,7^{\circ} \mathrm{C}$.

Ainda, considerando-se apenas a temperatura mínima média do mês mais frio $\left(\mathrm{Tmin}=18,2{ }^{\circ} \mathrm{C}\right.$ ), pode-se afirmar que na região de Araraquara, $\mathrm{SP}$, a probabilidade de ocorrência de geadas, apesar de possível, é baixa.

Classificação climática: De acordo com os dados analisados, verifica-se que a região, segundo a classificação climática de Köeppen, está numa faixa de transição entre o grupo climático Aw para o grupo Cwa, ou seja, apresenta características entre o clima tropical chuvoso (chuvas concentradas na estação de verão e com temperatura média do mês mais frio acima de
$18{ }^{\circ} \mathrm{C}$ ), e o clima tropical de altitude (verões quentes e estações secas de inverno, observando-se, ainda, que a temperatura média do mês mais quente é, para o município, superior a $10^{\circ} \mathrm{C}$ e que, a temperatura média do ar dos três meses mais frios estão compreendidas entre $-3{ }^{\circ} \mathrm{C}$ e $18{ }^{\circ} \mathrm{C}$ ).

Com relação aos trabalhos de mapeamento de solos, o primeiro passo constou da seleção de todo tipo de material existente sobre a área, compreendendo desde a seleção de mapas básicos em diferentes escalas até estudos gerais da região sobre os solos e matérias correlatas, tais como geologia, geomorfologia, clima e vegetação original. Ainda nessa etapa, contou-se com um mapa planialtimétrico da empresa florestal, em escala ao nível de detalhe. Foram feitos estudos preliminares dos mapas planialtimétricos, onde se determinaram os locais a serem visitados no campo. Efetuaram-se prospecções por meio de tradagens (trado tipo holandês) até $120 \mathrm{~cm}$ (200 cm quando fosse o caso) ou através de estudos em barrancos de estradas expostos, a intervalos regulares de 30 a 50 hectares, possibilitando o ajuste de uma legenda geral de unidades de mapeamento, de caráter preliminar. 
Nessas prospecções, teve-se o cuidado de registrar todas as variações referentes às classes de solos, incluindo, entre outras, cor, textura, gradiente textural, tipo e espessura dos horizontes A e B, profundidade do solum, posição do solo na paisagem, forma e comprimento das vertentes, altura do nível piezométrico, profundidade efetiva dos solos (ocorrência de material rochoso), etc.

Concomitantemente a essas observações, procedeuse a coleta de amostras de solos, em média, a cada 60 hectares e em duas profundidades: uma superficialmente e outra subsuperficialmente, respeitando-se os diferentes tipos de horizontes diagnósticos, para fins de análises químicas e granulométricas. Estas análises foram realizadas conforme manual de métodos e análises da Claessen (1997), e a classificação pedológica foi realizada segundo o Sistema Brasileiro de Classificação de Solos (SANTOS et al., 2006). Para georreferenciamento do mapa de solos, foi utilizado o software ArcGis 9.1 da ESRI. Utilizando-se rotinas do aplicativo ArcGis, foram digitalizadas as unidades de mapeamento de solos, definidas com base nos trabalhos de campo, e apresentadas na Tabela 2, com suas áreas (em hectares) e seu percentual relativo ao tamanho da fazenda. O mapa de declividade do terreno foi gerado a partir de curvas de nível, com equidistância de $5 \mathrm{~m}$. Inicialmente, criou-se um modelo digital de elevação do terreno (MDE) com base nos conceitos de malha triangular (TIN). Para tal, utilizaram-se como feição as cotas das curvas de nível, usando como forma de triangulação pontos em massa. A partir do MDE, definiram-se as classes de relevo: plano (0-3\%), suave ondulado (3-8 \%), ondulado (8-20\%) e forte ondulado (20-45\%). Não há classes de relevo superiores a $45 \%$.
A partir das informações contidas na legenda do levantamento detalhado de solos, procurou-se determinar as Unidades de Manejo Florestais Produtivas (UMP's) de forma estimativa para a área-piloto em estudo.

A metodologia adotada neste trabalho utiliza a modelagem por "Lógica Fuzzy" (STOLLE et al., 2009), onde primeiramente foram selecionadas algumas das variáveis disponíveis para o estudo. Em seguida, estas variáveis foram espacializadas para finalmente poder prosseguir com a determinação das Unidades de Manejo Na seqüência, os resultados obtidos foram comparados com os estimados pela prática dos autores. Para evitar que uma variável extremamente negativa compensasse igualmente outra extremamente positiva, foram adotados pesos diferenciados para cada uma das variáveis da rede "Fator Limitante" dos solos. Assim, considera-se que elas contribuem de maneira diferente na representação da Unidade de Manejo (Tabela 3).

Os valores dos domínios da função de pertinência "fuzzy" para as variáveis da rede "Fator Limitante" (Tabela 4) e os seus respectivos pesos (Tabela 5) foram determinados com base nas avaliações dos especialistas em mapeamento de solos deste presente trabalho. Deste modo, a análise da Unidade de Manejo propriamente dita foi realizada através da extensão $E M D S$ para o ArcGIS 9.0, tendo-se, primeiramente, adicionado todos os planos de informação (mapas vetoriais) da área de estudo e, em seguida, efetuada a leitura da base de conhecimento elaborada pelo software NetWeaver (programa de domínio público), para finalmente executar a análise. 
Tabela 2. Legenda geral de identificação das classes de solos da Fazenda Fortaleza, Propriedade da Conpacel, Município de Araraquara, SP.

\begin{tabular}{|c|c|c|c|}
\hline Simbolo & $\begin{array}{c}\text { Área } \\
\text { (ha) }\end{array}$ & $\begin{array}{l}\% \\
\text { Relativa }\end{array}$ & Unidades de Mapeamento de Solos \\
\hline $\mathrm{PVAd}_{3}$ & 56,7 & 1,2 & $\begin{array}{l}\text { ARGISSOLO VERMELHO-AMARELO Distrófico típico, A moderado, textura arenosa/média } \\
\text { leve, fase relevo ondulado. }\end{array}$ \\
\hline LVAd $_{1}$ & 254,9 & 5,5 & $\begin{array}{l}\text { LATOSSOLO VERMELHO-AMARELO Distrófico espessarênico, A moderado, textura média } \\
\text { leve, fase relevo plano ou suave ondulado. }\end{array}$ \\
\hline $\operatorname{LVAd}_{2}$ & 11,5 & 0,2 & $\begin{array}{l}\text { LATOSSOLO VERMELHO-AMARELO Distrófico típico, A moderado, textura média leve, fase } \\
\text { relevo suave ondulado. }\end{array}$ \\
\hline $\mathrm{LVd}_{1}$ & 117,2 & 2,5 & $\begin{array}{l}\text { LATOSSOLO VERMELHO Distrófico espessarênico, A moderado, textura média leve, fase relevo } \\
\text { plano. }\end{array}$ \\
\hline $\mathrm{LVd}_{2}$ & 58,7 & 1,3 & $\begin{array}{l}\text { LATOSSOLO VERMELHO Distrófico espessarênico, A moderado, textura média leve, fase relevo } \\
\text { suave ondulado. }\end{array}$ \\
\hline $\mathrm{LVd}_{3}$ & 172,6 & 3,7 & LATOSSOLO VERMELHO Distrófico típico, A moderado, textura média leve, fase relevo plano. \\
\hline $\mathrm{LVd}_{4}$ & 75,4 & 1,6 & $\begin{array}{l}\text { LATOSSOLO VERMELHO Distrófico típico, A moderado, textura média leve, fase relevo suave } \\
\text { ondulado. }\end{array}$ \\
\hline $\mathrm{LVd}_{7}$ & 26,8 & 0,6 & $\begin{array}{l}\text { LATOSSOLO VERMELHO Distrófico típico, A moderado, textura média pesada, fase relevo plano } \\
\text { ou suave ondulado. }\end{array}$ \\
\hline RQgf & 65,9 & 1,4 & $\begin{array}{l}\text { NEOSSOLO QUARTZARÊNICO Hidromórfico plíntico, A proeminente, textura arenosa }(<4 \\
\text { \%argila), fase relevo plano ou suave ondulado. }\end{array}$ \\
\hline $\mathrm{RQo}_{1}$ & 3000,7 & 64,4 & $\begin{array}{l}\text { NEOSSOLO QUARTZARÊNICO Órtico típico, A moderado, textura arenosa ( } 4-8 \% \text { argila), fase } \\
\text { relevo plano ou suave ondulado. }\end{array}$ \\
\hline $\mathrm{RQO}_{2}$ & 418,8 & 9,0 & $\begin{array}{l}\text { NEOSSOLO QUARTZARÊNICO Órtico típico, A moderado, textura arenosa ( } 8 \text { - } 15 \% \text { argila), } \\
\text { fase relevo plano ou suave ondulado. }\end{array}$ \\
\hline $\mathrm{RQo}_{3}$ & 225,4 & 4,9 & $\begin{array}{l}\text { NEOSSOLO QUARTZARÊNICO Órtico típico, A moderado, textura arenosa ( } 4-8 \% \text { argila), fase } \\
\text { relevo suave ondulado ou ondulado. }\end{array}$ \\
\hline $\mathrm{RQO}_{6}$ & 45,6 & 1,0 & $\begin{array}{l}\text { NEOSSOLO QUARTZARÊNICO Órtico típico, A proeminente, textura arenosa ( } 4 \text { - } 8 \% \text { argila), } \\
\text { fase relevo ondulado ou forte ondulado. }\end{array}$ \\
\hline $\mathrm{RQO}_{7}$ & 104,4 & 2,2 & $\begin{array}{l}\text { NEOSSOLO QUARTZARÊNICO Órtico léptico, A moderado, fase relevo suave ondulado ou } \\
\text { ondulado. }\end{array}$ \\
\hline $\mathrm{RLd}_{3}$ & 15,5 & 0,3 & Associação de NEOSSOLO LITÓLICO Distrófico típico + Afloramentos de Rochas. \\
\hline AR & 10,6 & 0,2 & AFLORAMENTOS DE ROCHAS. \\
\hline
\end{tabular}


Tabela 3. Detalhamento dos atributos de solo e relevo utilizados para estratificação das unidades de manejo produtivas para eucaliptos na Fazenda Fortaleza, Propriedade da Conpacel, no Município de Araraquara, SP.

\begin{tabular}{|c|c|}
\hline Atributo & Especificação \\
\hline 1. Textura & $\begin{array}{l}\text { Separa oito classes em termos de percentuais de argila, tanto da camada superficial quanto da camada } \\
\text { subsuperficial: 1) menor que } 4 \% ; 2 \text { ) entre } 4 \% \text { e } 8 \% ; 3 \text { ) entre } 8 \% \text { e } 15 \% \text { ) entre } 15 \% \text { e } 20 \% \text {; ) entre } \\
20 \% \text { e } 27 \% \text {;) entre } 27 \% \text { e } 35 \% \text {;) entre } 35 \% \text { e } 59 \% ; 8 \text { ) acima de } 60 \% \text { de argila; bem como separa em } \\
\text { duas classes texturais de espessuras das camadas: caráter típico e caráter espessarênico. }\end{array}$ \\
\hline $\begin{array}{l}\text { 2. Declividade do } \\
\text { terreno }\end{array}$ & $\begin{array}{l}\text { A declividade do terreno aliada à classe textural estima a condição do potencial de "capacidade de retenção } \\
\text { d'água". Ela separa em cinco classes: 1) plano } \leq 3 \% \text { declive; 2) entre } 3 \% \text { e } 8 \% ; 3 \text { ) entre } 8 \% \text { e } 20 \% \text {;) } \\
\text { entre } 20 \% \text { e } 45 \% ; 5) \geq 45 \% \text { de declive. }\end{array}$ \\
\hline 3. Teor de Nutrientes & 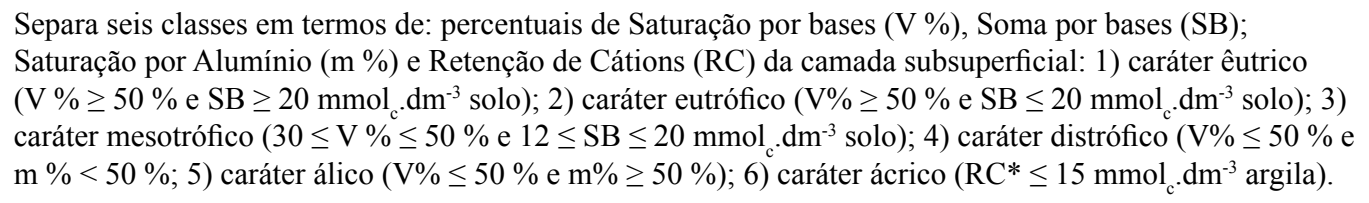 \\
\hline $\begin{array}{l}\text { 4. Profundidade } \\
\text { Efetiva (PEF) }\end{array}$ & $\begin{array}{l}\text { Separa em três classes: } 1) \text { solo profundo (PEF } \geq 100 \mathrm{~cm} \text {; 2) solo pouco profundo }(50 \mathrm{~cm} \leq P E F \leq 100 \mathrm{~cm}) \text { e } \\
\text { 3) solo raso }(50 \mathrm{~cm} \leq \mathrm{PEF} \leq 100 \mathrm{~cm}) \text {. }\end{array}$ \\
\hline 5. Aeração & Separa em três classes: a) Bem a Excessivamente Drenados; b) Moderadamente drenados; c) Mal drenados. \\
\hline
\end{tabular}

Tabela 4. Domínio das funções de pertinência "fuzzy" dos dados para a Fazenda Fortaleza, Propriedade da Conpacel, no Município de Araraquara, SP.

\begin{tabular}{lcc}
\hline \multicolumn{1}{c}{ Dados } & $\begin{array}{c}\text { Valor } \\
\text { Verdadeiro }\end{array}$ & $\begin{array}{c}\text { Valor } \\
\text { Falso }\end{array}$ \\
\hline Argila da camada superficial (\%) & 50 & 1 \\
Argila da camada subsuperficial (\%) & 50 & 1 \\
Declividade (\%) & 8 & 45 \\
Fertilidade 1 (V\%) & 65 & 10 \\
Fertilidade 2 (SB em mmol $\mathrm{dm}^{-3}$ ) & 20 & 12 \\
Profundidade efetiva do solo (cm) & 100 & 50 \\
Aeração (cm) & 100 & 50 \\
\hline
\end{tabular}

\section{Resultados e Discussão}

Considerando-se que para definição das UMP's através da técnica "Lógica fuzzy" o mapeamento detalhado dos solos da propriedade foi de fundamental importância para a conclusão do estudo, procurou-se compreender a grande variabilidade de solos existentes, resultantes da diversidade geológica e das formas de relevo na área-piloto em estudo, através da seleção dos
Tabela 5. Pesos utilizados para as variáveis da rede "Fator Limitante" na Fazenda Fortaleza, Propriedade da Conpacel, no Município de Araraquara, SP.

\begin{tabular}{ll}
\multicolumn{1}{c}{ Variáveis } & Peso \\
\hline Argila da camada subsuperficial & 40 \\
Argila da camada superficial & 30 \\
Profundidade Efetiva & 25 \\
Aeração & 10 \\
Declividade & 5 \\
Fertilidade 1 (V\%) & 5 \\
Fertilidade 2 (SB) & 3 \\
\hline
\end{tabular}

atributos que pudessem ser definidos como os principais para a distinção dos diferentes ambientes.

Apoiados na integração do conhecimento da cultura do eucalipto e solos, definiram-se as UMP's. Esta área-piloto, que tem o predomínio de solos arenosos, sugere classes de Unidades de Manejo com moderada a baixa capacidade produtiva para o eucalipto pela pequena capacidade de retenção de água, uma vez que é potencializada pelas condições climáticas, ou seja, 
pela estação seca definida, que é bastante longa para esta região de estudo.

O resultado obtido para a determinação das Unidades de Manejo via "Lógica Fuzzy", relatados a seguir, apresentou conclusões semelhantes ao esperado, considerando apenas as condições do meio físico.

\section{Unidades de Manejo Produtivas para Eucaliptos}

Com base na metodologia aplicada, foram feitos os agrupamentos das classes de solos e das características do meio físico (principalmente, as classes de declives) em Unidades de Manejo Produtivas (UMP's) para a área-piloto em estudo.
Verifica-se, pela Figura 2 e Tabela 6, que ocorreram na Fazenda Fortaleza as seguintes UMP's: UMP II (26,8 ha $=7,0 \%)$, UMP III $(1.108,9$ ha $=54,7 \%)$ e UMP IV $(56,7$ ha $=38,4 \%)$, UM V $(3.457,5$ ha $=54,7 \%)$ e UM VI $(10,6$ ha $=38,4 \%)$ " . Elas estão descritas na Tabela 6 , onde se pode comprovar a estimativa e a tendência de diferenças em termos de produtividades das espécies do gênero objeto deste estudo, pelos possíveis fatores limitantes associados às diferentes capacidades produtivas.

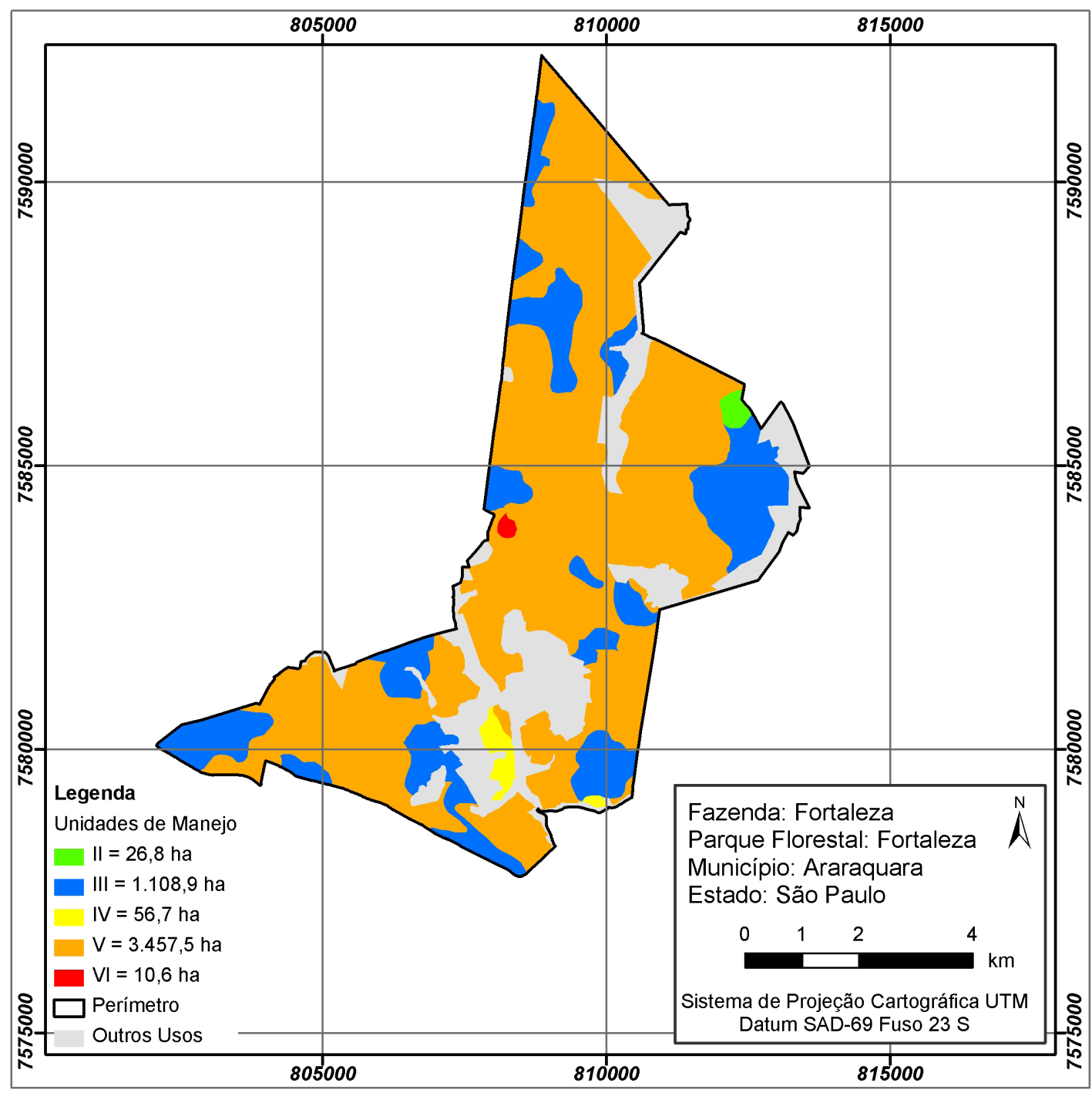

Figura 2. Mapa Detalhado das Unidades de Manejo Produtivas para Eucaliptos, na Fazenda Fortaleza, Propriedade da Conpacel, Município de Araraquara, SP. 
Tabela 6. Classes de Solos e Unidades de Manejo Produtivas (UMP's) estabelecidas com base nos Critérios de Estratificação ("Lógica Fuzzy") para a Área-Piloto - Fazenda Fortaleza, Propriedade da Conpacel, Município de Araraquara, SP.

\begin{tabular}{|c|c|c|c|c|}
\hline UMP & $\begin{array}{c}\text { Área } \\
\text { (ha) }\end{array}$ & $\begin{array}{c}\% \\
\text { Relativa }\end{array}$ & Características & Classes de Solos \\
\hline I & 0,0 & 0,0 & $\begin{array}{l}\text { Solos com caráter típico e sem gradiente textural, textura argilosa ou } \\
\text { muito argilosa; muito profundos; bem a excessivamente drenados e } \\
\text { ocorrendo em relevos suave ondulados a ondulados (com declives } \\
\text { inferiores a } 12 \% \text { ). Destacam-se como superiores os solos na seguinte } \\
\text { ordem decrescente, em termos de teores de carbono orgânico superficial: } \\
\text { A chernozêmicos }>\text { A húmico }>\text { A proeminente (úmbricos) }>\text { A } \\
\text { moderado. }\end{array}$ & $\begin{array}{l}\text { NVef, } \operatorname{LVdf}_{1}, \operatorname{LVdf}_{2}, \\
\mathrm{NVdf}, \mathrm{NVd}_{1}, \mathrm{NXd}_{1}, \\
\mathrm{NXd}_{2}, \operatorname{LVd}_{8}, \operatorname{LVd}_{9}, \\
\operatorname{LVd}_{10}, \operatorname{LVd}_{11}, \operatorname{CXbd}_{6}, \\
\operatorname{MTf}_{1}, \operatorname{LVAd}_{11}, \operatorname{LVAd}_{12} \\
\text { e CHbd }\end{array}$ \\
\hline II & 102,9 & 2,2 & $\begin{array}{l}\text { Solos com textura: a) argilosa (argila } \geq 35 \% \text { ), média }(25 \leq \% \text { argila } \\
\leq 35 \text { ), caráter típico e sem gradiente textural; b) média/argilosa } \\
\text { (eutróficos), com gradiente textural, não abrúpticos; profundos; ou } \\
\text { c) solos com textura média ou média pesada; bem a excessivamente } \\
\text { drenados; todos ocorrendo em relevos suave ondulados ou ondulados. }\end{array}$ & $\mathrm{CXbd}_{3}, \mathrm{PVAe}_{5} \mathrm{e} \mathrm{LVAd}_{7}$ \\
\hline III & & 23,8 & $\begin{array}{l}\text { Solos com ou sem caráter espessarênico de textura média leve, ou de } \\
\text { textura areia franca nos limites para a classe textural média, ou com } \\
\text { textura arenosa/média ou arenosa/média pesada (eutróficos ou não); com } \\
\text { gradiente textural, abrúpticos ou não. Também fazem parte desta unidade } \\
\text { de manejo os solos pouco profundos de textura média distróficos e sem } \\
\text { gradiente textural. Ainda, os solos com textura areia franca no limite } \\
\text { para textura média leve. Todos os solos são bem a excessivamente } \\
\text { drenados, ocorrendo em relevos suave ondulados a ondulados. }\end{array}$ & $\begin{array}{l}\mathrm{LVd}_{1}, \mathrm{LVd}_{2}, \mathrm{LVd}_{3}, \\
\mathrm{LVd}_{4}, \mathrm{LVAd}_{1}, \mathrm{LVAd}_{2}, \\
\mathrm{LVAd}_{5}, \mathrm{LVAd}_{6}, \mathrm{CHbd}_{3}, \\
\mathrm{CXbd}_{2}, \mathrm{CXbd}_{7}, \mathrm{RQo}_{2}, \\
\mathrm{RQo}_{8}, \mathrm{RQo}_{9}, \mathrm{RQo}_{10}, \\
\mathrm{RQo}_{11}, \mathrm{PVAe}_{1}, \mathrm{PVAd}_{2}, \\
\mathrm{PVAd}_{4}, \mathrm{PVAd}_{5}, \mathrm{PVAd}_{6}, \\
\mathrm{PEe}_{1}, \mathrm{PEe}_{2}, \mathrm{PEe}_{3}, \mathrm{PEd}_{1}, \\
\mathrm{PEd}_{2}, \mathrm{PEd}_{3} \mathrm{PEd}_{6} .\end{array}$ \\
\hline IV & 56,7 & 1,2 & $\begin{array}{l}\text { Solos eutróficos: a) com textura arenosa/média pesada (relevos suave } \\
\text { ondulado a ondulados), b) de textura argilosa (relevos ondulado ou forte } \\
\text { ondulados). Solos com textura média }(25 \leq \% \text { argila } \leq 35) \text {, arenosa/ } \\
\text { média ou arenosa/média pesada (distróficos) com gradiente textural, } \\
\text { abrúpticos ou não. Também fazem parte desta unidade de manejo os } \\
\text { solos com textura média leve (sem gradiente textural) ou solos com } \\
\text { textura arenosa } 2 \text { ( } 8 \% \text { a } 15 \% \text { de argila). Todos ocorrendo em relevos } \\
\text { suave ondulados a ondulados, bem a excessivamente drenados e/ou mal } \\
\text { drenados, quando de textura argilosa. }\end{array}$ & $\begin{array}{l}\text { PVAd }_{1}, \mathrm{PVAd}_{3}, \mathrm{PEd}_{4} \text {, } \\
\text { PEd }_{5}, \mathrm{CXbd}_{5}, \mathrm{CXbd}_{8} \text {, } \\
\text { GMd, RQo } \\
{ }_{12}, \mathrm{RLd}_{1}, \mathrm{RLe} \\
\text { e RLm }\end{array}$ \\
\hline $\mathbf{V}$ & 3.381 & 72,6 & $\begin{array}{l}\text { Solos pertencentes à classe textural areia franca, ou seja, com textura } \\
\text { arenosa } 2(8-15 \% \text { argila) até pelo menos } 150 \mathrm{~cm} \text { de espessura do } \\
\text { perfil. Enquadram-se nesta classe os solos rasos, de textura média que } \\
\text { ocorrem em relevos forte ondulados e/ou suave ondulados associados a } \\
\text { afloramentos rochosos. Também pertencem a esta unidade de manejo os } \\
\text { solos com textura arenosa (teor de argila inferior a } 8 \%) \text {, até pelo menos } \\
150 \mathrm{~cm} \text { de espessura do perfil, relevo plano ou suave ondulado, bem a } \\
\text { mal drenados, bem como, os solos com gradiente textural abrúpticos } \\
\text { com caráter plíntico. }\end{array}$ & $\begin{array}{l}\mathrm{PAd}_{1}, \mathrm{RQo}_{1}, \mathrm{RQo}_{3}, \\
\mathrm{RQo}_{4}, \mathrm{RQo}_{5}, \mathrm{RQo}_{6}, \\
\mathrm{RQo}_{7}, \mathrm{RQg}_{1}, \mathrm{RQg}_{2}, \\
\mathrm{RQg}_{\mathrm{f}}, \mathrm{RLd}_{2} \mathrm{e} \mathrm{RLd}_{3} .\end{array}$ \\
\hline VI & 10,6 & 0,2 & Área inapta para a cultura do eucalipto. & $\mathrm{AR}$ \\
\hline
\end{tabular}

Os cinco grupos estabelecidos priorizam os solos de maior relevância para o manejo florestal e para o melhoramento genético, sendo que para este último, a importância maior está na interação entre solo-plantaatmosfera, representado pela dinâmica da água do solo e na indicação de melhores clones e/ou espécies.
Verifica-se que as UMP's determinadas via “Lógica Fuzzy", para a área de estudo, tiveram a mesma tendência de estimativa empírica do potencial de produtividade. 


\section{Conclusões}

A técnica utilizada se apresentou apropriada na definição de unidades de manejo utilizando dados do meio físico, uma vez que os resultados obtidos com a "Lógica Fuzzy" foram semelhantes aos estimados na prática.

\section{Referências}

CARVALHO, J. R. de P; VIEIRA, S. R.; MORAN, R. C. C. P. Como avaliar similaridade entre mapas de produtividade. $1^{\mathrm{a}}$. ed. Campinas: Relatório técnico/Embrapa informática agropecuária 10, 2001.

CAVAGUTI, N.; SILVA, F. P. Gestão dos Recursos Hídricos Subterrâneos na cidade de Bauru - SP: Face as Características Hidrogeológicas Epeciais da Região. In: CONGRESSO BRASILEIRO DE ÁGUAS SUBTERRÂNEAS, 7., 1992, Belo Horizonte. Anais...., Belo Horizonte, MG. p. 74-79.

CLAESSEN, M. E. C. (Org.). Manual de métodos de analise de solo. 2.ed. rev. atual. Rio de Janeiro: EMBRAPA-CNPS, 1997. 212 p. (EMBRAPA-CNPS. Documentos, 1)

COLVIN, T. S.; JAYNES, D. B.; KARLEN, D. L.; LAIRD, D. A.; AMBUEL, J. R. Yield variability within a central Iowa field. Transaction of the ASAE, St. Joseph, v. 40, n. 4, p. 883-889, 1997.

GONÇALVES, J. L. M. Interações genótipo-ambiente e relações entre a produtividade de sítios florestais de $E$. grandis e $E$. saligna com as propriedades de alguns solos de textura arenosa e média no Estado de São Paulo. 1990. 135 f. Tese (Doutorado em Agronomia) - Escola Superior de Agricultura Luiz de Queiroz, Universidade de São Paulo, Piracicaba.
KITCHEN, N. R.; SUDDUTH, K. A. DRUMMOND, S. T. An evaluation of methods for determining site-specific management zones. In: PROCEEDINGS NORTH CENTRAL EXTENSIONINDUSTRY SOIL FERTILITY CONFERENCE, 28., 1998. St. Louis. v. 14, p. 133-139. St. Louis, MO. S. Dak.: Potash and Phosphate Institute.

LORUP, E.J. IDRISI WWW tutorial: map pairs tools II. Disponível em: < http://geo.skku.ac.kr/ skkugis/data/idrtutor.pdf >. Acesso em: 26 out. 2003.

MOLIN, J. P. Definição de unidades de manejo a partir de mapas de produtividade. Engenharia Agrícola, Jaboticabal, v. 22, n. 1, p. 83-92, 2002.

RESENDE, M.; CURI, N.; REZENDE, S. B. de; CORRÊA, G. F. Pedologia: base para distinção de ambientes. Viçosa: NEPUT, 2007. 304p.

SANTOS, H. G. dos; JACOMINE, P. K. T.; ANJOS, L. H. C. dos; OLIVEIRA, V. A. de; OLIVEIRA, J. B. de; COELHO, M. R.; LUMBRERAS, J. F.; CUNHA, T. J. F. (Ed.). Sistema brasileiro de classificação de solos. 2. ed. Rio de Janeiro: Embrapa Solos, 2006. 306 p. il. Inclui apêndices.

STOLLE, L.; LINGNAU, C.; ARCE, J. E.; BOGNOLA, I. A. Aplicação de um sistema baseado em conhecimento e lógica fuzzy para o mapeamento da fragilidade ambiental em relação às atividades florestais. Anais...14 $4^{\circ}$ Simpósio Brasileiro de Sensoriamento Remoto, p.3103-3110. Natal: INPE, 2009.

SUDDUTH, K.A.; DRUMMOND, S. T.; BIRRELL, S. J.; KITCHEN, S. J. Spatial modeling of crop yield using soil and topographic data In: EUROPEAN CONFERENCE ON PRECISION AGRICULTURTE,1., 1997, Warwick University, UK. Oxford: Bios Scientific, 1997. v. 1, p. 439-447. v. 1 Precision agricultue'97 - Spatial variability in soil and crop.

THORNTHWAITE, C. W.; MATTER, J. R. The water balance. Centerton: Drexel Institute of Technology, 1955. 104 p. (Drexel Institute of Technology. Publications in Climatology, v. 8, n. 1).

Recebido em 16 de novembro de 2009 e aprovado em 09 de dezembro de 2009 